\title{
PENGARUH PERSEPSI DAN NILAI NASABAH \\ TERHADAP TINGKAT KEPERCAYAAN BANK \\ (Studi Pada Nasabah Bank BPR Syariah Di Kota Semarang)
}

\author{
Ch. Asta Nugraha \\ Fakultas Ekonomika Dan Bisnis UNTAG Semarang \\ Email : chastanugraha@gmail.com \\ Joko Riyanto \\ Fakultas Ekonomika Dan Bisnis UNTAG Semarang \\ Email :joko_heri18@yahoo.com \\ Imam Gozali \\ Fakultas Ekonomika Dan Bisnis UNTAG Semarang \\ Email :gozali313@gmail.com
}

\begin{abstract}
Abstrak
Bank BPR syariah yang digerakkan dengan sistem bagi hasil serta orientasi maslahah (kebaikan) dan kehalalan telah mendorong kompetisi perbankan yang bertumpu pada bunga. Namun begitu, kepercayaan masyarakat untuk berinvestasi melalui perbankan syariah masih relatif rendah. Ini menjadi latar untuk melakukan penelitian tentang apa penyebab rendahnya kepercayaan masyarakat terhadap perbankan syariah. Persepsi dan nilai nasabah menjadi orientasi peneliti menduga penyebab tinggi rendahnya tingkat kepercayaan Bank (BPR) Syariah di Kota Semarang. Tujuan penelitian ini adalah untuk mengetahui pengaruh persepsi dan nilai nasabah terhadap kepercayaan bank BPR Syariah di Kota Semarang. Penelitian ini menggunakan metode kuantitatif dengan analisis regresi. Instrumen dalam pengumpulan data menggunakan kuesioner dengan teknik non probability sampling berdasarkan convenience sampling yaitu berdasarkan kemudahan ditemui tanpa membedakan responden muslim dan non-muslim terhadap 100 responden. Hasil penelitian menyimpulkan bahwa persepsi dan nilai nasabah berpengaruh positif dan signifikan terhadap tingkat kepercayaan bank.
\end{abstract}

Kata kunci: persepsi, nilai, kepercayaan

\section{Abstract}

$B P R$ syariah bank is driven by the sharing system as well as the orientation maslahah (kindness) and halal banking has encouraged competition resting on an interest. However, public confidence to invest in Islamic banking is still relatively low. This is the backdrop to do research on what causes of low public confidence in the Islamic banking. Perception and value customers into high orientation researchers suspect causes low levels of trust banks (BPR) Sharia in Semarang. The purpose of this study was to determine the effect of the perception and value of customers' confidence BPR Syariah bank in Semarang. This study uses a quantitative method by regression analysis. Instruments in data collection using a questionnaire with non-probability sampling technique based Convenience Sampling is based on the ease encountered regardless moslem and non-moslem respondent on 100 respondents. The study concluded that the Customer Perception and Customer value had positive and significant impact on the level of Bank Trust.

Keywords: perception, value, trust 


\section{PENDAHULUAN}

\section{Latar belakang masalah}

Kepercayaan terhadap suatu perusahaan telah dikaji beberapa peneliti misalnya Morgan dan Hunt, (1994) Kepercayaan adalah penentu utama dari komitmen suatu hubungan, dan kepercayaan ada ketika ada keyakinan dalam kehandalan mitra dan integritas. Selanjutnya (Bachri, 2007) mengatakan kepercayaan dipandang sebagai unsur mendasar bagi keberhasilan suatu kemitraan. Apabila kemitraan itu tidak didasari oleh suatu kepercayaan maka hubungan kemitraan itu tidak akan bertahan lama. Ia juga mengatakan bahwa komponen kunci dari kepercayaan adalah sejauh mana pelanggan percaya bahwa perusahaan memiliki niat dan motif bermanfaat bagi pelanggan dan prihatin dengan menciptakan hasil yang positif kepada pelanggan. Jadi kepercayaan merupakan kesediaan untuk mengandalkan pada mitra pertukaran yang satu memiliki keyakinan.

Hal lain yang mempengaruhi pelanggan (nasabah) dalam memilih suatu produk atau jasa, adalah faktor budaya (culture), sosial (social), pribadi (personal), dan faktor psikologis (psychological factor) (Kotler \& Armstrong, 2006). Konsep nilai pelanggan (nasabah) memberikan gambaran tentang pelanggan suatu perusahaan, mempertimbangkan apa yang mereka inginkan, dan percaya bahwa mereka memperoleh manfaat dari suatu produk Nilai-nilai yang ada dalam diri individu merupakan isi dari aspek budaya. Nilai-nilai individu dalam memilih produk/jasa berdimensi nilai emosional, nilai sosial, nilai kinerja, nilai harga (Sweeney and Soutar dalam Tjiptono, 2005)

Di sisi lain, persepsi pelanggan (nasabah) terhadap perusahaan perbankan merupakan penilaian menyeluruh atas keunggulan (kualitas) jasanya. Keunggulan yang dipersepsikan merupakan konsep unidimensional (Bachri, 2007) yaitu penafsiran konsumen yang mencakup persepsi yang beragam. Terkait dengan persepsi beragam ini, Parasuraman et.al (1998) misalnya telah mengungkapkan dan merangkum dalam 5 (lima) dimensi pokok yaitu: reliability, responsiveness, assurance, empathy, tangible.

Dengan latar inilah, penelitian ini dilakukan untuk mengungkapkan bagaimana persepsi dan nilai nasabah bank memberikan kepercayaan kepada bank BPR yang berdasar syariah dapat lebih marketable di masa yang akan datang?

\section{Perumusan masalah}

1. Bagaimana pengaruh persepsi terhadap kepercayaan pada Bank BPR syariah di Kota Semarang?

2. Bagaimana pengaruh nilai nasabah terhadap kepercayaan pada Bank BPR Syariah di Kota Semarang?

\section{Tujuan Penelitian}

1. Untuk mengetahui pengaruh persepsi terhadap kepercayaan nasabah pada Bank BPR syariah di Semarang

2. Untuk mengetahui pengaruh nilai nasabah terhadap kepercayaan pada Bank BPR Syariah di Kota Semarang

\section{HIPOTESIS DAN MODEL PENELITIAN}

\section{Hubungan Persepsi dan Kepercayaan Bank}

Menurut Gibson, (2004) Persepsi sebagai suatu prosess cognitive yang dipergunakan oleh seorang untuk menafsirkan dan memahami dunia sekitarnya. Individu mengorganisasikan dan menafsirkan kesan-kesan indera mereka memaknai obyek atau lingkungan yang dilihatnya (Robbins, 2001). Lingkungan yang dipersepsikan adalah lingkungan yang penting dari segi perilaku, dalam hal ini adalah perbankan syariah (BPR syariah). Seseorang individu akan memandang BPR syariah dan mencoba menafsirkan apa yang dilihatnya. Penafsiran itu sangat dipengaruhi oleh karakteristik pribadi, sehingga beberapa individu memandang obyek yang sama 
namun menghasilkan persepsi berbeda, oleh karena itu persepsi mempunyai sifat subyektif. Diantara karakteristik pribadi yang memengaruhi persepsi adalah sikap, motif, kepentingan, pengalaman masa lalu dan pengharapan (Robbins, 2001). Jika hasil persepsi terhadap BPR Syariah itu baik maka akan meningkatkan kepercayaan bank.

H1 : Ada pengaruh positif persepsi nasabah terhadap kepercayaan BPR Syariah Di Semarang

\section{Hubungan Nilai Nasabah dan Keper- cayaan Bank}

Nilai pelanggan adalah preferensi yang dirasakan oleh pelanggan atas atribut produk, kinerja, dan konsekuensi yang timbul dari pemakaian fasilitas untuk memenuhi sasaran dan maksudnya. Dengan nilai nasabah yang tinggi akan mempengaruhi tingkat kepercayaan Bank.

$\mathrm{H} 2$ : Ada pengaruh positif nilai nasabah terhadap kepercayaan bank BPR Syariah Di Semarang

\section{Penelitian Terdahulu}

Penelitian terdahulu dalam penelitian ini dapat dijelaskan pada Tabel 1.

\section{Model Penelitian}

Melihat potensi masyarakat Semarang masih sangat besar untuk menumbuhkembangkan bank syariah, maka model penelitian yang diajukan dapat dijelaskan pada Gambar 1.

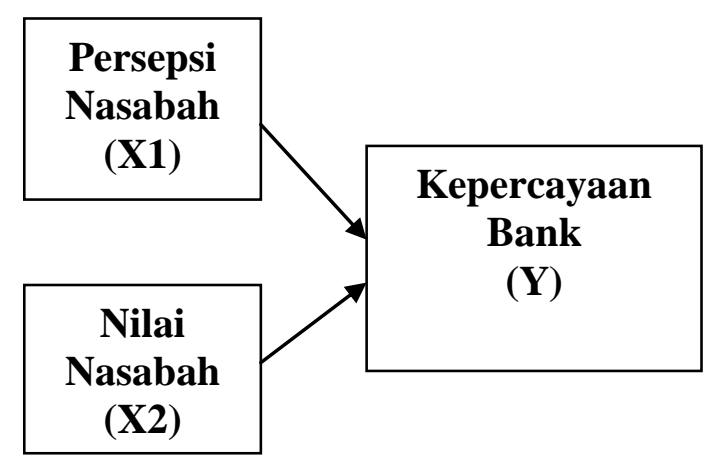

Gambar 1. Model penelitian ini

Tabel 1. Penelitian Terdahulu

\begin{tabular}{|c|c|c|c|c|}
\hline No & $\begin{array}{l}\text { Peneliti } \\
\text { (Tahun) }\end{array}$ & Judul & $\begin{array}{c}\text { Alat } \\
\text { Analisis }\end{array}$ & Hasil \\
\hline 1 & $\begin{array}{l}\text { Bachri, } \\
2007\end{array}$ & $\begin{array}{l}\text { Analisis } r \text { Kualitas } \\
\text { layanan, kepuasan dan } \\
\text { kepercayaan nasabah } \\
\text { pada Bank Syariah di } \\
\text { Kota Makassar }\end{array}$ & SEM & $\begin{array}{lc}\text { Kualitas } & \text { layanan } \\
\text { berpengaruh positif terhadap } \\
\text { kepuasan dan terhadap } \\
\text { kepercayaan } \\
\text { terhadap Bank Syariah }\end{array}$ \\
\hline 2 & $\begin{array}{l}\text { Haryadi } \\
\text { (2007) }\end{array}$ & $\begin{array}{lr}\text { Persepsi } & \text { masyarakat } \\
\text { terhadap } & \text { perbankan } \\
\text { syariah } & \end{array}$ & Regresi & $\begin{array}{l}\text { Faktor pengetahuan, manfaat } \\
\text { keuangan, pelayanan dan } \\
\text { lokasi berpengaruh terhadap } \\
\text { perilaku masyarakat di } \\
\text { wilayah Eks Karesidenan } \\
\text { Banyumas terhadap bank } \\
\text { syariah }\end{array}$ \\
\hline
\end{tabular}

\section{METODE PENELITIAN}

\section{Lokasi penelitian}

Penelitian ini dilakukan di Kota Semarang dengan obyek penelitian Bank BPR Syariah.

\section{Definisi Konsep dan Indikator}

Definisi konsep dan indikator dapat dijelaskan pada Tabel 2. 
Tabel 2. Definisi konsep dan indikator

\begin{tabular}{|c|c|c|c|}
\hline No & Variabel & Definisi Konsep & Indikator \\
\hline 1 & Persepsi & $\begin{array}{l}\text { Persepsi adalah proses memberi } \\
\text { arti terhadap lingkungannya. } \\
\text { Individu mengorganisasikan dan } \\
\text { menafsirkan kesan-kesan indera } \\
\text { mereka memaknai obyek atau } \\
\text { lingkungan yang dilihatnya } \\
\text { (Robbins, 2001) }\end{array}$ & $\begin{array}{l}\text { 1. Kesan-kesan terhadap wujud } \\
\text { institusi bank syariah } \\
\text { 2. Kesan terhadap pelayanan bank } \\
\text { syariah } \\
\text { 3. Kesan terhadap SDM bank } \\
\text { syariah } \\
\text { 4. Kesan terhadap sistem bank } \\
\text { syariah }\end{array}$ \\
\hline 2 & $\begin{array}{l}\text { Nilai } \\
\text { nasabah }\end{array}$ & $\begin{array}{l}\text { Nilai nasabah atau pelanggan } \\
\text { adalah preferensi yang dirasakan } \\
\text { oleh pelanggan atas atribut } \\
\text { produk, kinerja, dan konsekuensi } \\
\text { yang timbul dari pemakaian } \\
\text { fasilitas untuk memenuhi sasaran } \\
\text { dan maksudnya (Susanto dalam } \\
\text { Vanessa, 2007) }\end{array}$ & $\begin{array}{l}\text { 1. Emotional value } \\
\text { 2. Social value } \\
\text { 3. Performance value } \\
\text { 4. Price/value of money }\end{array}$ \\
\hline 3 & $\begin{array}{l}\text { Keperca- } \\
\text { yaan }\end{array}$ & $\begin{array}{l}\text { Kepercayaan adalah penentu } \\
\text { utama dari komitmen suatu } \\
\text { hubungan (Morgan dan Hunt, } \\
\text { 1994). Kepercayaan adalah } \\
\text { kesediaan untuk mengandalkan } \\
\text { pada mitra pertukaran yang satu } \\
\text { memiliki keyakinan. (Moorman } \\
\text { et al., 1993) }\end{array}$ & $\begin{array}{l}\text { 1. Nasabah percaya bahwa perusa- } \\
\text { haan memiliki niat dan motif } \\
\text { bermanfaat bagi pelanggan } \\
\text { 2. Menciptakan hasil yang positif } \\
\text { kepada nasabah/pelanggan }\end{array}$ \\
\hline
\end{tabular}

\section{Teknik Pengumpulan Data}

Sumber data yang dikumpulkan dalam penelitian ini antara lain data primer diperoleh langsung oleh pengumpul data dengan menyebar kuesioner, dan data sekunder, dari publikasi jurnal dan pustaka ilmiah. Adapun populasi dalam penelitian ini yaitu nasabah yang menggunakan jasa BPR Syariah di Kota Semarang. Metode pengambilan sampel dengan non random sampling, yaitu penentuan unit sampel tidak acak berdasarkan pada unit populasi yang kebetulan ditemui peneliti (Indriantoro dan Supomo, 2002) dengan berdasar Convenience Sampling yaitu berdasarkan kemudahan ditemui (Istijanto, 2009) pada penelitian ini pertimbangan pengambilan sampel nasabah bank BPR Syariah tanpa membedakan responden muslim dan non muslim, dimana besarnya sampel yang digunakan dalam penelitian ini adalah 100 responden

\section{Uji Validitas dan Reliabilitas}

Uji validitas digunakan untuk mengukur sah/valid tidaknya suatu questioner. Suatu questioner dikatakan valid jika pertanyaan pada questioner mampu untuk mengungkapkan sesuatu yang diukur oleh questioner tersebut (Ghozali, 2009).

Sedangkan uji reliabilitas dilakukan untuk mengukur konsistensi konstruk/ variabel penelitian suatu kuesioner dikatakan reliable/handal jika jawaban seseorang terhadap pertanyaan adalah konsisten/stabil dari waktu ke waktu. Suatu variabel dikatakan reliable jika memiliki Cronbach alpha > 0,6 (Ghozali, 2009).

\section{Uji Asumsi Klasik \\ Uji Normalitas}

Uji normalitas bertujuan untuk menguji apakah dalam model regresi, 
variabel terikat dan variabel bebas keduanya mempunyai distribusi normal atau tidak. Model regresi yang baik adalah memiliki distribusi data normal atau mendekati normal. Untuk menguji apakah distribusi data normal atau tidak, salah satu cara termudah untuk melihat normalitas adalah melihat histogram yang membandingkan antara data observasi dengan distribusi yang mendekati distribusi normal. Namun demikian dengan hanya melihat histogram hal ini bisa menyesatkan khususnya untuk jumlah sampel yang kecil. Metode yang lebih handal adalah dengan melihat normal probability plot yang membandingkan distribusi kumulatif dari data sesungguhnya dengan distribusi kumulatif dari distribusi normal. Distribusi normal akan membentuk satu garis lurus diagonal, dan ploting data akan dibandingkan dengan garis diagonal. Jika distribusi data adalah normal, maka garis yang menggambarkan data sesungguhnya akan mengikat garis diagonal (Ghozali, 2002).

\section{Autokorelasi}

Uji ini bertujuan untuk menguji apakah dalam suatu model regresi terdapat korelasi residual pada periode saat ini (t) dengan residual pada periode sebelumnya (t-1) (Ghozali, 2002).

\section{Heteroskedastisitas}

Uji ini bertujuan menguji apakah dalam model regresi terjadi ketidaksamaan varian residual dari satu pengamatan ke pangamatan yang lain. Jika varian residual dari satu pengamatan ke pangamatan yang lain tetap maka disebut homokesdastisitas dan jika berbeda disebut heteroskedastisitas (Ghozali, 2002). Salah satu uji heteroskedastisitas yang digunakan adalah uji Glejser yaitu dengan meregresikan nilai absolut residual terhadap variabel bebasnya. Jika variabel bebas signifikan secara statistik mempengaruhi variabel terikat maka terdapat indikasi terjadinya heterokedastisitas.

\section{Alat analisis data}

Alat analisis yang digunakan dalam penelitian ini adalah regresi linear. Langkah pertama dalam analisis data kuantitatif dimulai dengan analisis regresi linier berganda sebagai berikut: (Sujana, 1992):

$$
\begin{aligned}
& \text { Dimana: } \\
& \mathrm{Y}=\mathrm{a}+\mathrm{bX} 1+\mathrm{bX} 2+\mathrm{e} \\
& \mathrm{X} 1=\text { Pepercayaan nasabah } \\
& \mathrm{X} 2=\text { Nilai nasabah/pelanggan } \\
& \mathrm{a}=\text { konstanta } \\
& \mathrm{b}=\text { koefisien dari variabel bebas }(\mathrm{X}) \\
& \mathrm{e}=\text { faktor pengganggu }
\end{aligned}
$$

\section{Uji Goodness of fit Model}

Koefisien determinasi $\left(\mathrm{R}^{2}\right)$ pada intinya untuk mengukur seberapa jauh kemampuan model dalam menerangkan variasi variabel dependen/tidak bebas. Nilai koefisien determinasi adalah antara nol (0) dan satu (1). Nilai $\mathrm{R}^{2}$ yang kecil berarti kemampuan variabel-variabel independen (bebas) dalam menjelaskan variasi variabel dependen amat terbatas. Nilai yang mendekati satu berarti variabelvariabel independen memberikan hampir semua informasi yang dibutuhkan untuk memprediksi variasi variabel dependen (Ghozali, 2009).

\section{Uji Hipotesis}

Menurut Ghozali (2009), uji hipotesis atau uji statistik t pada dasarnya menunjukkan seberapa jauh pengaruh satu variabel independen secara individual dalam menerangkan variabel dependen. Pengujian dilakukan dengan menggunakan significance level 0,05 ( $\mathrm{a}=5 \%)$. Penerimaan atau penolakan hipotesis dilakukan dengan kriteria sebagai berikut:

- Jika nilai signifikan >0,05 maka hipotesis ditolak (koefisien regresi tidak signifikan). Hal ini berarti bahwa secara parsial variabel independen tersebut tidak mempunyai pengaruh yang signifikan terhadap variabel dependen. 
- Jika nilai signifikan $\leq 0,05$ maka hipotesis diterima (koefisien regresi signifikan). Hal ini berarti secara parsial variabel independen tersebut mempunyai pengaruh yang signifikan terhadap variabel dependen.

\section{HASIL PENELITIAN DAN PEMBA- HASAN}

\section{Uji Validitas dan Reliabilitas}

Berdasarkan olah data SPSS untuk pengujian validitas pada variabel bebas $(\mathrm{X})$ dan variabel terikat (Y) diketahui nilai $r$ hitung > $\mathrm{r}$ tabel, maka semua instrumen (item pertanyaan /indikator) dinyatakan valid. Artinya pertanyaan dalam kuesioner yang telah dibuat benar-benar dapat mengukur apa yang akan diukur, sehingga layak untuk digunakan sebagai instrumen penelitian.

Berdasarkan olah data SPSS diketahui semua variabel nilai Cronbach Alphanya di atas 0,6. Hal ini berarti semua konsep pengukuran masing-masing variabel dalam kuesioner adalah reliabel. Artinya, jawaban seseorang terhadap pernyataan adalah konsisten atau stabil dari waktu ke waktu sehingga selanjutnya item-item pada masing-masing konsep variabel tersebut layak digunakan sebagai alat ukur pada penelitian ini.

\section{Hasil Uji Asumsi Klasik}

\section{Uji Normalitas}

Uji normalitas dilakukan untuk melihat apakah nilai residual terdistribusi dengan normal atau tidak. Uji normalitas dengan melihat normal probability plot memenuhi standar normal membentuk garis diagonal. Hasil uji normalitas dapat dilihat pada Gambar 2.

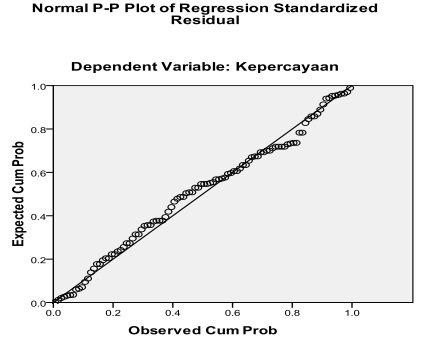

Gambar 2. Uji Normalitas
Dengan melihat tampilan grafik normal plot terlihat titik-titik menyebar di sekitar garis diagonal, serta penyebarannya mengikuti arah garis diagonal. Grafik ini menunjukkan bahwa model regresi layak dipakai karena memenuhi asumsi normalitas.

\section{Autokorelasi}

Berdasarkan hasil analisis regresi, diperoleh nilai Durbin-Watson (DW) sebesar 1,611. Sedangkan nilai du diperoleh sebesar 1,57. Dengan demikian diperoleh bahwa nilai DW sebesar 1,611 tersebut lebih besar 1,57 dan kurang dari 1,65 (du), maka dapat disimpulkan bahwa tidak terdapat autokorelasi dalam model regresi tersebut.

\section{Heteroskedastisitas}

Hasil uji heteroskedastisitas dapat dilihat pada Gambar 3. Dari grafik scatterplots terlihat titik menyebar secara acak dan tersebar baik di atas maupun di bawah angka 0 pada sumbu Y. Hal ini menunjukkan tidak terjadi heteroskedastisitas pada model regresi, sehingga model regresi layak digunakan untuk memprediksi kepercayaan Bank BPR Syariah berdasarkan persepsi dan nilai nasabah

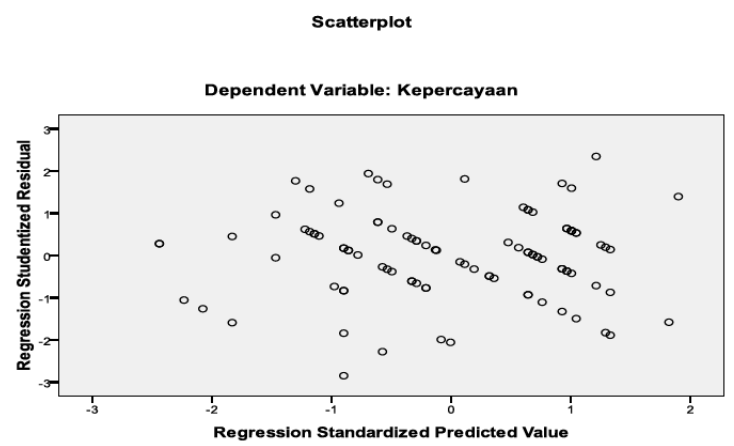

Gambar 3. Uji Heteroskedastisitas

\section{Analisis Regresi}

Hasil analisis regesi dapat dilihat pada Tabel 3. 
Tabel 3. Hasil Analisis Regresi

\begin{tabular}{lrrrrr}
\hline Model & \multicolumn{2}{c}{$\begin{array}{l}\text { Unstandardized } \\
\text { Residual }\end{array}$} & $\begin{array}{l}\text { Standardized } \\
\text { Coefficients }\end{array}$ & t & Sig. \\
\hline & $\mathrm{B}$ & Std. Error & Beta & & \\
\hline (Constant) & 0.085 & 0.468 & & 0.182 & 0.856 \\
\hline Persepsi & 0.387 & 0.054 & 0.740 & 7.216 & 0.000 \\
\hline Nilai Nasabah & 0.054 & 0.067 & 0.082 & 0.802 & 0.425 \\
\hline
\end{tabular}

F Hitung $=91.362$ Sig. $=0.000$

$\mathrm{R}^{2}=0.653$ Adjusted $\mathrm{R}^{2}=0.653$

Dari hasil olah data pada Tabel 3 ditemukan model regresi sebagai berikut: $\mathrm{Y}=0.085+0,387 \mathrm{X} 1+0,054 \mathrm{X} 2$

\section{Uji Model}

Nilai Adjusted R Square pada Tabel 3 sebesar 0,653 cenderung mendekati angka 1 sehingga persepsi dan nilai nasabah mampu menjelaskan sebagian besar kepercayaan bank BPR Syariah. Dari hasil yang didapat tersebut juga dapat diartikan pula bahwa persepsi dan nilai nasabah mampu menjelaskan sebagian besar kepercayaan bank BPR Syariah sebesar 65,30\%, sedangkan sebesar $34,70 \%(100 \%$ - 65,30\%) kepercayaan bank BPR Syariah dipengaruhi oleh variabel lain di luar persepsi dan nilai nasabah.

Dari perhitungan dengan menggunakan SPSS 17.00 pada Tabel 3 diperoleh $\mathrm{F}$ hitung sebesar 91.362 dengan $\mathrm{p}$ value $=0,000<0,05$ sehingga dapat ditarik kesimpulan bahwa model persamaan regresi linier berganda adalah signifikan, artinya variabel-variabel tersebut (persepsi nasabah dan nilai nasabah layak digunakan untuk memprediksi kepercayaan bank BPR syariah.

\section{Uji hipotesis}

Hasil uji hipotesis melalui uji $\mathrm{t}$ pada Tabel 3 dapat dijelaskan sebagai berikut:

H1 : Ada pengaruh persepsi nasabah terhadap kepercayaan bank BPR syariah.

Hasil uji - t (uji parsial) pengaruh persepsi nasabah terhadap kepercayaan bank BPR syariah diperoleh $t_{\text {hitung }} 7.216>t_{\text {tabel }} 0,309$, dengan sig. 0,000 .
Nilai sig. yang didapat $<\alpha=0,05$ yang berarti menerima $\mathrm{H}_{1}$, yakni persepsi nasabah berpengaruh terhadap kepercayaan bank BPR syariah dan berarti.

$\mathrm{H} 2$ : Ada pengaruh nilai nasabah terhadap kepercayaan bank BPR syariah.

Hasil uji - $\mathrm{t}$ (uji parsial) pengaruh nilai nasabah terhadap kepercayaan bank BPR syariah diperoleh $t_{\text {hitung }} 0,801>t_{\text {tabel }} 0,309$. Namun demikian tidak signifikan karena Sig $0,425>\alpha=0,05$ yang berarti menerima $\mathrm{H}_{2}$ artinya, ada pengaruh positif nilai nasabah terhadap kepercayaan bank BPR syariah namun tidak atau kurang

\section{KESIMPULAN DAN SARAN Kesimpulan}

Dari hasil analisis data dan pembahasan dapat disimpulkan :

1. Terdapat pengaruh persepsi terhadap kepercayaan Bank BPR Syariah di Kota Semarang.

2. Terdapat pengaruh nilai nasabah terhadap kepercayaan Bank BPR Syariah di Kota Semarang, namun tidak signifikan.

3. Variabel Persepsi dan Nilai Nasabah mampu menjelaskan sebagian besar kepercayaan bank BPR Syariah sebesar $65,30 \%$.

\section{Saran}

Adapun saran yang dapat diberikan adalah sebagai berikut:

1. Bank BPR syariah kota Semarang agar lebih meningkatkan lagi dalam membangun persepsi citra bank yang terpercaya dengan meningkatkan peran 4 indikator persepsi. 
2. Meskipun nilai nasabah tidak signifikan pengaruhnya terhadap kepercayaan bank syariah namun hal ini tidak berarti bank mengabaikan nilainilai nasabah dalam operating system bank syariah. Justru harus tetap komitmen menjaga differensitas sebagai bank berbasis syariah Islam dengan meningkatkan peran 4 indikator nilai nasabah.

\section{DAFTAR PUSTAKA}

Antonio, M.S. (1999). Bank Syariah bagi bankir dan praktisi keuangan. Diterbitkan atas kerja sama Bank Indonesia dan Tazkia Institute, Jakarta.

Antonio, M.S. (2001). Bank Syariah: Dari teori ke praktek. Jakarta: Gema Insani.

Arikunto, S. (2002). Prosedur Penelitian. Jakarta: Rineka Cipta.

Bachri, S. (2007). Analisis Kualitas layanan, kepuasan dan kepercayaan nasabah pada Bank Syariah di Kota Makassar. Jurnal Ekonomi Dan Manajemen, 8(2).

Ghafar, V. (2007). Customer Relationship Management and Marketing Public Relation. Bandung: Alfabeta.

Ghozali, I. (2005). Aplikasi Analisis Multivariate Dengan Program SPSS. Semarang: Badan Penerbit Universitas Diponegoro.

Ghozali, I. (2009). Aplikasi Analisis Multivariate Dengan Program SPSS. Semarang: Badan Penerbit Universitas Diponegoro.

Gibson, J. L. (2004). Perilaku, Struktur dan Proses. Jakarta: PPM.
Haryadi. (2007). Persepsi masyarakat terhadap perbankan syariah. Jurnal Bisnis dan Manajemen, 7(2), 129204.

Indiyantoro, N. \& Supomo, B. (2002). Metodologi Penelitian Bisnis. Yogyakarta: BPFE.

Kotler, P., \& Armstrong, G. (2006). Principles of Marketing, Eleventh Edition, New Jersey: Prentice Hall.

Monroe, K. B. (2003). Pricing Making Profitable Decisions. Third Edition. Singapura: McGraw Hill. Jakarta: Gramedia Pustaka Utama.

Morgan, M. J. \& Hunt, R. (1994). Pioneering and Market Share: Is Entry Time Endogenous and does it Matter. Journal of Marketing $X X V(97)$.

Parasuraman, A., Berry, L., \& Zeithaml, V. (1991). Perceived Service Quality as a Customer-based Performance Measure: An Empirical Examination of Organizational Barriers Using an Extended Service Quality Model. Human Resource Management, 30(3), 335-364.

Parasuraman, A., Zeithaml, V.A., \& Berry, L.L. (1988). Servqual A multiple item scale for measuring consumer perceptions of service quality. Jurnal of retailing, 64(1), 12-40.

Robbins, S. (2001). Perilaku Organisasi, Jilid 1, Jakarta: Prenhallindo

Santoso, S., \& Tjiptono, F. (2001). Riset Pemasaran : Konsep dan Aplikasi dengan SPSS. Jakarta: PT. Elex Media Komputindo.

Singarimbun, M. \& Effendi. (1989). Metodologi Penelitian Survey. Jakarta: LP3S 
Sudjana. (1992). Teknik Analisis Regresi dan Korelasi Bagi Para Peneliti, Bandung.

Sugiyono. (2001). Metode Penelitian Administrasi. Bandung: Alfabeta.

Susanto, A. B. (2004). Power Branding: Membangun Brand Yang Legendari. Jakarta: PT. Mizan Pustaka.

Tjiptono, F. \& Gregorius. (2005). Service Quality dan Satisfaction. Yogyakarta: Andi Ofset.

Umar, H. (2003). Metode Penelitian Aplikasi dalam Pemasaran. Jakarta: PT. Gramedia Pustaka Utama.

Zeithaml, V. A, Leonard L. B. \& Parasuraman, A. (1996). Behavioral Consequences of Service Quality. Journal Of Marketing, 60(April), 7087.

Zeithmal, V. A., Bery, L.L., \& Parasuraman, A. (1993). The Nature and Determination of Customer expectations of service. Journal of Academy Of Marketing Science, 21, 1-12. 